\title{
ROLE CHANGES ASSOCIATED WITH WIDOWHOOD AMONG MIDDLE AND UPPER-CLASS WOMEN
}

Jeanne M. Gibbs

Pre-Doctoral Trainee, Midwest Council for Social Research in Aging Kansas State University

Mid-American Review of Sociology, 1978, Vol. 3 No. 2:17-33

This research explores the role changes for a segment of widows that may be associated with their perceptions of widowhood. Face-to-face, in-depth, standardized interviews were administered during 1973 and early 1974 to a selected sample of 30 middle and upper-class widows living in the Kansas City Standard Metropolitan Statistical Area. Interviews focused on five traditional women's roles, as perceived before and after widowhood, and on the changes which occurred in these roles as attributed to widowhood. The data indicate that role-filling and compensating behavior include assumption of former husband's responsibilities (financial management, home maintenance, etc.), renewal or acceleration of work careers, renewal or acceleration of organizational activity, travel and other relatively individualized activities, and adjustment of role relationships with relatives and others. The women interviewed were educated, had no major health constraints and, for the most part, had no financial constraints; therefore, they have the resources and abilities to re-create their life situations after widowhood, once the initial period of grief is over. The general impression from the sample is that these women have or will turn to roles which essentially contain "secondary" type relations when they perceive that there are no roles containing "primary" relations in which they can function.

In itself, the process of aging involves major changes and transitions for the individual. Health decline, retirement, decreased income, disintegration of the nuclear family, and widowhood are but a few of the changes persons may have to face and deal with as they age. These life changes may involve role changes.

(I would like to thank Hyman Mariampolski, Alan Johnson and two anonymous referees for editorial assistance and helpful criticism for earlier drafts. Responsibility for content, however, remains solely with the author.) 
The intent of this research is to investigate the self-perceived role changes that may occur among a sample of middle and upper-class women living in the Kansas City SMSA in response to a crisis and/or a major life transition. Specifically, an attempt was made to delineate those self-perceived role changes which these women have undergone as a result of the deaths of their husbands.

Sociological research in the area of role changes in widowhood has gained some attention in the last several years. The foundation and framework established by Lopata (1970; $1971 ; 1973 \mathrm{a} ; 1973 \mathrm{~b})$ on this topic guides this study.

According to Znaniecki (1965), social role is defined as being a "set of functionally interdependent, patterned relations between a social person and the participants in his social circle, consisting of his duties and the personal rights that they grant him in order that he be able to carry out his part" (Lopata, 1973:1-2). A social role involves a fluid and continuous process. New roles are created and 'old' ones discarded as a person's life stage changes, producing altered self-perceptions which will influence new or altered behavioral patterns. Kent (1968:26-27) points out that "role changes occur, for all of us, throughout life but most tend toward increasing role specificity and increasing role specialization." However, Kent insists that such is not the case for the older American; instead, there is usually a reduction not only of role content but also of the number of roles played.

The increasing life span of adults, especially women, has heightened the need for widowhood research. "Annual mortality rates remain higher for men than for women, having decreased by only 3.1 per 1,000 for men aged $65+$ since 1940 compared to 10.5 per 1,000 for women of the same age" (U.S. Bureau of Census; 1972a:55). According to 1972 census data, there were $9,601,000$ widowed women in the United States who constituted 12.1 percent of the total population of women at that time (U.S. Bureau of Census; 1972b:13). Thus widows, according to Steinhart (1972:1), "are a sizable and easily recognizable group who are faced with similar structural problems and characteristics."

\section{THE METHOD}

This paper is based upon data collected in metropolitan Kansas City during 1973 and early 1974. Face-to-face, in-depth, standardized interviews were administered to a non-random sample of 30 widowed women who were considered to be middle to upper-class by virtue of their education, current income, residential value and location. Interviews focused on five traditional women's roles before and after widowhood and the degree to which role changes were attributed to widowhood.

A snowball sample of middle and upper-class widows was obtained with the assistance of a minister, a banker, and the respondents themselves. Potential respondents were selected after recommended individuals' class characteristics were assessed. Eight respondents were chosen during the course of the study at the suggestion of those who had completed the interview. These were usually friends and/or relatives of respondents.

Potential respondents were telephoned by myself, the minister or the banker. At this time, the women were informed of the purposes of the study, the manner in which their names were obtained and were asked if they would consent to a confidential interview. There was only one refusal. Once cooperation was obtained, an appointment for an initial face-to-face interview was arranged with the respondent. At an initial meeting of about one-half to one hour in length, the respondent was informed in more detail about the study, was shown the interview instrument, and was asked to think about the questions for 'a day or so.' Another appointment was later arranged to complete the interview. This second meeting was approximately one to two hours in length.

The questionnaire contained closed format questions on contextual variables and a set of open-ended questions on the changes in particular roles before and after widowhood. Five traditional role areas for women were explored: mother/householder, wife, worker, organizational member, and daughter/daughter-in-law. Additional open-ended questions concerned the major decisions that had to be made upon 
becoming widowed. We also sought information on who helped most in post-widowhood decisions and the advice which the respondent would give to a new widow. Finally, we had the respondent assess the relative importance of the role areas.

\section{SAMPLE CHARACTERISTICS}

All the respondents in this study were female, Caucasian, middle to upper-class widows who had not yet remarried. The respondents ranged in age from 39 to 86 years with an average of 66.4 years. The average age at widowhood for the sample was 55.6 years. Most respondents $(\mathrm{N}=25)$ perceived themselves as being in 'good' health and five women considered their health as 'fair.' The average educational achievement for the sample was 15.3 years (very high according to national averages). Twenty-four respondents had attended college for one or more years. Of these respondents, eighteen had one or more college degrees, thirteen had bachelor's degrees, three had master's degrees, one had a LL.B., and one had a Ph.D.

The respondents were also asked if they had any business education, either formal or informal, especially in the areas of investment, stocks, insurance or other related areas. This type of knowledge, it was felt, would contribute to a widow's ability to cope with matters involving financial decisions with which she might be faced following her husband's death. Twenty-three of the respondents reported they had some knowledge in this area, while seven respondents reported they had no business education, either formal or informal.

The respondents were asked to estimate their current annual income. The current average annual income for the sample was $\$ 12,300$. Twenty-two respondents were Protestant, especially Methodist and Presbyterian denomination. Six women were Catholic and two were Jewish. Length of marriage for the sample ranged from 4 years to 51 years, the average length being 29.2 years. Length of widowhood ranged from 1 year to 43 years, the average length being 10.7 years.

\section{REPORTED ROLE CHANGES IN VARIOUS SOCIAL ROLES}

\section{Mother and/or Householder Role}

Sixty percent of the sample reported changes in the mother and/or householder role areas after widowhood, and a majority of these reported changes involved the role of householder. All respondents considered themselves as 'head of household' at the time of the interviews. Of the 30 women interviewed, twenty-two lived alone while the other eight shared their residence with others (usually related others).

The most often mentioned change as householder ( $N=14)$ was the assumption of duties and/or responsibilities concerning the household which the husband had previously performed or had arranged to have done. For example, when asked what changes she had encountered as a householder since she became widowed, one woman said:

It became my responsibility for all the upkeep; replacement of equipment such as the furnace and other items women know little about. No one was as deeply interested in these things as was your spouse.

This group of women was not as concerned about the financial operation or management of finances for the house as they were about the performance of maintenance and upkeep duties. Having repairs done on the home, especially getting someone to do them properly without overcharging, was the most often mentioned problem in the householder role. $(\mathrm{N}=15)$. One respondent said she had "learned to get at least three estimates for any work or any item since many people feel they can take advantage of a dumb widow." Most respondents reported they either attempted to do the repairs themselves or else made arrangements for them to be done.

Only six women in the sample reported changes in their role as a mother, though twenty-four said they had children. The 
reason for such a small number reporting change in this area was attributed to the fact that for most of these women their children were grown and had moved away by the time the women became widows.

Different functional tasks are posed to a mother according to the ages of her children when she is widowed. Of the women reporting changes in the mother role, five had young children still residing in the home at the time of widowhood. One respondent reported that while she had no children of her own, she adopted two young children after she was widowed and therefore felt that for her the mother role involved great changes due to the initiation of this role after her husband's death. ${ }^{1}$

The major change for a widowed mother of small children still dependent on her, according to this sample, is that after the loss of the husband as the father and partner in the child rearing process, the mother feels the responsibility of caring for, supporting and raising the children alone yet with the added responsibility of fulfilling duties contained in the father's role. As one woman who had been left with three young children said:

I immediately experience more responsibility. I felt the double role of being mother and also carrying out the wishes of my husband for the children and my way of life.

It should be noted that over one-third of the sample reported 'no change' in either role area of 'mother' or 'householder.' Two reasons were given for these 'no change' responses. First, the repondent had no children (six reported they had no children) and did not feel the householder role had changed, since she felt she had taken care of the major portion of the household operation responsibilities and management during her marriage and continued 'just as before' after widowhood. Second, the respondent had children but stated her children were grown at the time of widowhood, and consequently felt that her child rearing responsibilities were over and that she had taken care of the household responsibilities during the marriage and continued to do so after widowhood.
Regardless of whether or not role changes occurred, most of the widowed mothers reported a greater reliance on children (regardless of their ages), especially for emotional support, after widowhood.

\section{Wife Role}

All respondents reported changes in the role of wife due to and since widowhood. At the time of the interviews, none of the respondents had remarried since widowhood, but one-third of the sample, when asked if they would consider remarriage, expressed the desire to remarry.

Over a third of the women (N=11) felt the wife role had been terminated for them due to widowhood. One woman stated that for her the termination of the role occurred almost immediately.

The greatest change, I would say that from the time the doctor told my husband had 'expired' I never again felt like a wife. I felt like a widow RIGHT THEN

Other comments about the termination of this role were: "This role ended nine years ago" (the time at which her husband died). "When your husband dies, this role no longer exists."

It should be mentioned that the responses of the women indicated they did not necessarily consider themselves 'single.' Rather, the impression was that these women considered themselves the remaining partner of a marriage, and felt they had the responsibility of fulfilling some of the duties associated with being a wife, such as maintaining the home and relations with children, relatives and friends of their former husband.

The change in the wife role mentioned most often by the respondents was that they no longer had a partner or companion to share various aspects of their lives. Twenty-six women mentioned their deceased husband as a specific person with whom they had shared daily interaction. For these women, the loss of 
their husband as a primary person, perhaps the primary person in their 'social circle,' had a pronounced impact. As one woman expressing this loss said:

It took awhile to get over expecting to hear that 'Happy Good Morning,' to hear the door latch as he returned at eventide, to have him lean over my shoulder to help with a crossword puzzle, to catch him practicing at the pool table, ... to hear the loving tone in 'That's my girl!' when I'd burn the rolls or do some other stupid thing. He'd prepared me for the mechanics of 'living on' but this other-a person can't be prepared for!!

For this woman, as for most of the respondents, the lack of daily exchange(s) of casual remarks and conversational interaction with a specific person created an irreparable void in their lives. According to the respondent's perceptions, the loss of their husband as a partner or companion was particularly acute for certain activity areas such as daily interaction and activity with one close and significant person, attending social functions as a 'couple,' rearing children, or traveling together. Changes in social activities which had previously centered around the spouse also created changes in friendships for the widow. The pattern from this sample seems to be that social activities changed from evening to daytime hours, and that friendships changed from including both men and women to including primarily women. Over half of the women interviewed reported that one of their problems was not having a male escort to social occasions, especially an escort to evening funetions: As one said when she was asked about the changes and problems widowhood had created for her:

When I think of the problems of widowhood-I think more in terms of the loss of the husband as a social partner and companion for me.

The friendships are different after widowhood. They changed drastically. We had friendships mainly with other married couples and now I'm friends with only women on a social level and only the daytime hours say from 8 a.m. to 5 p.m. Now with a couple, I feel like a 'fifth wheel.'

\section{Worker Role}

Fifty percent of the sample reported increased work activity after widowhood and felt their work had helped to compensate for role losses experienced since widowhood, especially for the losses which had occurred in the mother/householder and wife roles. When asked about the changes that had occurred in the work role, one woman commented about her increased emphasis and activity in this role by saying:

Yes, I became more aggressive in the worker role. I was free to be aggressive in business. Work became a bigger part of my life after widowhood. It helped fill my time and kept me busy.

Five respondents reported they had not worked during their marriage but began working after widowhood. Three of these women had returned to school and upon completion of graduate degrees taught school. ${ }^{2}$

Six women had co-owned a business in partnership with their husbands. At the time of the interviews, all six had sold or dissolved these businesses, but four continued to work after widowhood by seeking other employment.

Altogether, nineteen women stated they had worked at some time since their widowhood. However, at the time of the interviews, only fourteen were currently working, ten in full-time jobs and four on a part-time basis. Seven of those who were working at the time of the interviews said they began their present job after they were widowed. It should be mentioned that four respondents who had worked full-time during their marriage quit work once they became widows and seven women reported they had not worked either during their marriage or after they were widowed.

The general impression from the interviews seems to be that the worker role is one in which the widows have been able to compensate for other role losses, especially roles involving primary relations such as wife, mother and daughter/daughter-in-law. What 
seems to have occurred for some women is that once they perceived major losses in a primary relations role area, they turned to a secondary relations role area such as work for compensation, believing that no other primary relations role or roles were available.

\section{Organizational Member Role}

For this study, the role of organizational member pertained to the respondent's activities in voluntary organizations. Such organizational groups included: social, religious, civic, philanthropic, and service organizations. From the respondents' discussions, it appears that four factors have affected their organizational involvement. Those factors were: 1) the respondent's length of residence in Kansas City; 2) her educational achievement; 3) her income; and 4) her prior organizational involvement before widowhood.

Length of residence in the Kansas City area, it was felt, related to how well the respondent was 'grounded' in her community and was knowledgeable as to the organizational opportunities available to her. Education was considered to be indicative of the respondent's ability and/or skills for organizational involvement. Income of the respondent was also considered an important factor in her ability to become and maintain involvement in organizations.

During the course of the interviews, it became apparent that the widow's prior organizational involvement before widowhood had some effect on her involvement in organizations after widowhood.

One-third of the sample reported that the change experienced by them in this role was increased organizational activity and for most this was because they now 'had more time available' for organizations. This change was reported by one woman who said:

This role changed a good deal. As I stated before, I had not been too active (in organizations) before my husband's death but after his death I needed things to do. I was suddenly free to join organizations as I now had time to participate in them.

Eleven women reported their organizational activity changed in that they decreased their activity after widowhood. The primary reason given for decreased organizational activity was that the woman had belonged to organizations during her marriage because of her husband's membership, and his death precipitated the 'dropping' of these organizations since she now had 'no male escort' and/or 'simply lost interest' in these activities without him.

Much like the worker role area, the organizational member role seems to be one in which role-filling and compensating activity has been a feasible alternative for losses experienced in other role areas. Furthermore, this role area can also be one in which the widow experiences losses due to the death of her husband, especially if she had belonged to organizations during her marriage in conjunction with her husband's membership.

\section{Daughter/Daughter-In-Law Role}

The daugher and/or daughter-in-law role questions in the interview pertained to the respondent as being either a daughter or daughter-in-law, or perhaps both, after widowhood. The focus of inquiry in this role area was on perceived role changes which may have occurred with the respondent's parents, parents-in-law, or both, after widowhood.

Even though the majority of the sample felt the role of daughter or -daughter-in-law did not apply because they had neither parents nor parents-in-law living at the time they were widowed, it should not be ignored that for those to whom this role did apply, it was considered by them to be an important role area after widowhood. This was especially true for the women who had a parent living in their home at the time of and subsequent to their widowhood, and for the respondents who had a parent or parent-in-law living near them.

Especially for the eleven women closely identifying with this role, the person involved in the role with the respondent was or 
TABLE 1

had been a person with whom the respondent could compensate, relationally and behaviorally, for some losses experienced by her, particularly in the mother and wife roles.

\section{FINAL QUESTIONS}

In the final phase of the interview, the respondents were asked three questions concerning their widowhood, but these questions were not directed specifically to any of the role areas which had been discussed. These questions were: 1 ) What were the major decisions that you had to make upon becoming a widow? 2) Who helped you most with these decisions? 3) Do you have any advice for a new widow? While these questions were not concerned with any one role area in particular, it was thought that the responses to these three questions would give further insight into the changes that occurred within the various social role areas after widowhood.

The major decisions for these respondents related to decisions within the mother/householder role, especially the householder role (see Table 1). Most often mentioned major decisions were: "whether to remain in my home," and "financial decisions (investment and property)." These decisions were followed, in terms of their frequency of response, by decisions in the wife role, worker role and organizational member role respectively.

According to the tabulation of responses as to the person or persons who helped the widow most with her major decisions, the widow cited herself most often, followed by her children, änd then by family members other than her children (see Table 2). The impression is that the widow turned first to persons within her own social circle whom she felt could help her with major decisions not only because she could trust them, but also because they would be emotionally supportive of her new situation. These persons were usually related to her. However, reliance on persons outside her social circle was also shown when the widow felt that a person, specifically a professional person, had technical ability beyond that of herself or her family members to help her with these decisions.
Summary of Responses to the Question: "What were the major decisions that you had to make upon becoming a widow?"

Response

No. Reporting

To stay in my home.

Financial decisions (property and/or investment).

Whether to live alone or not.

How to best support my family.

To continue to work.

To establish friendships and keep close to my children.

Managing the children.

Funeral arrangements.

To make the best of the situation.

What to do with time.

To continue 'clubbing.'

11

1

1
1

1

1

$\mathrm{N}=30$

TABLE 2

Summary of Responses to the Question: "Who helped you most with these decisions?"

\begin{tabular}{lc}
\hline Response & No. Reporting \\
Myself & 11 \\
My Children & 7 \\
Family (other than children) & 5 \\
Professionals & 5 \\
Widow Friends & 1 \\
Minister & 1 \\
& $\mathbb{N}=30$
\end{tabular}


The responses to the question asking whether the respondents had any advice for a new widow were varied; however, some recurrent themes were evident. Table 3 shows the responses given to this question and the number of respondents mentioning the response.

\section{TABLE 3}

Summary of Responses to the Question: "Do you have any advice for a new widow?" By Categories of Responses.

\begin{tabular}{lc}
\hline Response & No. Times \\
& 10 \\
Be dependioned \\
Keep busy. & 10 \\
Be slow to make any major decisions/changes. & 8 \\
Consider others. & 8 \\
Be cautious about financial and business decisions. & 3 \\
Trust in God/have (religious) faith. & 3 \\
\end{tabular}

\section{Ranking of Roles}

At the end of the interview, the respondents were asked to rank the five role areas they had discussed in the order of greatest to least role changes they had experienced since becoming widows. Table 4 presents the rank order of the role areas as reported by the respondents.

\section{TABLE 4}

Rank Order of Social Role Areas By Respondents In Order of Greatest Role Changes (Number 1) Experienced After Widowhood to Least Role Changes (Number 5) Experienced After Widowhood.

$\begin{array}{cl}\text { Rank Order } & \text { Social Role Area } \\ 1 & \text { Wife } \\ 2 & \text { Worker } \\ 3 & \text { Organizational Member } \\ 4 & \text { Mother/Householder } \\ 5 & \text { Daughter/Daughter-In-Law }\end{array}$

\section{SUMMARY}

This research was intended to explore the role changes for a specific segment of widows that may be associated with their widowhood based upon their perceptions. Face-to-face, in-depth, standardized interviews were administered to a selected sample of 30 middle and upper-class widows. Interviews focused on five traditional women's roles before, after, and as attributed to widowhood.

The data indicate that among role-filling and compensating behavior are the following:

1) assumption of former husband's responsibilities (financial management, home maintenance, etc.),

2) renewal or acceleration of work careers

3) renewal or acceleration of organizational activity, travel and other relatively individualized activities,

4) adjustment of role relationships with relatives and others.

The women interviewed were educated, had no major health constraints and, for the most part, had no financial constraints; therefore, they had the resources and initiative to re-create their life situations after widowhood, once the initial period of grief was over, to a similarily satisfactory level as experienced before their widowhood.

The general impression from the sample is that these women have or will turn from roles which contain more intimate and personal behavioral expectations to role relations which essentially are more impersonal and not as intimate in the behaviors expected; particularly, when they perceive there are no longer intimate or personal role relations left for them in which to function. However, the reader is cautioned about the generalizability of the findings due to the limited and specific nature of the sample. 
Further focus on middle and upper-class widowhood will be useful. Additionally, lower socioeconomic class differences among the widowed should be explored. Differences among men and women by varying social class is another area which should be given attention. Further investigation might also center on the impact widowhood has for other family related roles and by the varying ages of family members. For instance, how does widowhood affect the role expectations and behaviors of a mother or a father by the variance of children's ages. Certainly different role behaviors and expectations are required when young children are in the home in contrast to whether the children are grown, gone from the home or child rearing tasks are no longer necessary due to other circumstances. Given the fact that average life expectancies are increasing, especially for women, the reality of intergenerational widowhood becoming increasingly more common looms larger and larger. Certainly the implications and special problems which this poses for the family deserves attention. It is hoped, then, that further research in these areas, as well as others in widowhood, will be forthcoming.

\section{NOTES}

1. This woman stated that she was the first woman, considered legally 'single,' to adopt children in the state of Missouri.

2. The two women who taught on the secondary education level after widowhood completed Master's degrees prior to teaching but after they were widowed. The woman who taught at the college level after widowhood completed a Ph.D. degree prior to teaching but after she was widowed.

\section{REFERENCES}

Kent, Donald $P$.

1968 "Aging Within the American Social Structure." Journal of Geriatric Psychiatry (2), (Fall):19-32.

Lopata, Helena $Z$.

1970 "The Social Involvement of American Widows." American Behavioral Scientist (14), (Fall):41-58.

1971 "Living Arrangements of American Urban Widows." Sociological Focus (5), (Autumn):41-61.

\section{Role Changes}

1973a Widowhood in An American City. Cambridge, Massachusetts: Schenkman Publishing Co., Inc.

Steinhart, Frank A.

1973b "Self-Identity in Marriage and Widowhood." The Sociological Quarterly (14), (Summer):407-418.

1972 "Correlates of Occupational Aspirations, Expectations and Choice in Adult Widows in the Chicago SMSA," Unpublished Ph.D. Dissertation Proposal, Department of Sociology, Loyola University.

U.S. Bureau of Census

1972a "Selected Life Table Values: 1939 to 1969." Statistical Abstract of the United States: 1972 (93rd Edition), Table No. 75, Washington, D.C.: U.S. Government Printing Office.

1972b "Marital Status and Living Arrangements: March 1972." Current Population Reports (Series P-20), Washington, Znaniecki, Florian D.C.: U.S. Government Printing Office.

1965 Social Relations and Social Roles. San Francisco: Chandler Publishing Co. 